\title{
INSECT PHYSIOLOGY AND APPLIED ENTOMOLOGY
}

\begin{abstract}
A
MEETING of the Association of Applied Biologists, held in the rooms of the Royal Entomological Society of London on October 12, was devoted to "Insect Physiology in Relation to Applied Biology". Dr. V. B. Wigglesworth was in the chair.

In opening the discussion, Dr. Wigglesworth claimed that insect physiology makes no direct contribution to applied entomology. The control of insect pests by biological methods is based upon ecology ; but a proper understanding of the ecology of an insect is impossible without a knowledge of its physiology. The practical value of this knowledge lies in the new ideas that it gives to the applied entomologist. Similarly, all the greatest discoveries in the use of insecticides have been made empirically. But the subsequent study of the diverse physiological mechanisms involved in insecticidal action has served to codify our knowledge, to put it on a rational basis and to point the way to further advances.
\end{abstract}

The study of insecticidal action may be pursued at three levels : the uptake of insecticides from the environment, their passage through the protective coverings of the insect or its egg, and the intervention of insecticidal poisons in metabolism. Dr. W. A. L. David discussed the physiological and anatomical factors involved in the accumulation of contact insecticides. The movement of the insect plays a most important part; and, as Dr. E. A. Parkin pointed out later in the discussion, the insecticide may itself influence the insect's movement and so the quantity of poison it acquires. Insects walking on a treated surface will pick up increased amounts of poison. The fine droplets that compose insecticidal mists will strike the insect only if they have sufficient momentum or if the insect itself is moving rapidly enough. They are, indeed, effective as a rule only if the insect is in flight, and, since the wings of flies or mosquitoes commonly move at least ten times as fast as the body, by far the greater number of droplets are taken up by the beating wings. Many difterent factors have to be considered in the accumulation of insecticidal dusts by insects. Some dusts are physically bulky, others dense; and the appearance of the treated insect may give a totally mis. leading impression of the weight of dust accumulated. In the case of rough or hairy insects, large amounts of the dust collected may be quite out of contact with the effective sites of entry; and with a single species of insect the same amount of the active principle accumulating on the body may be more effective when associated with one carrier than with another, because the shape of the dust particle has an important influence in ensuring contact with the vulnerable areas.

Dr. J. W. L. Beament pointed out that recently acquired knowledge of the structure of the cuticle and egg-shell of insects goes some way to explain the variable toxicity of contact poisons. In both the cuticle and the egg-shell a thin layer of wax forms the most important burrier; an insecticide must dissolve in wax and have a suitable partition coefficient between oil and water. Local differences in the structure of the membranes demand detailed study. In the egg of Heteroptera, for example, the general surface is totally impermeable to the most potent poisons. But around the rim of the cap are respiratory ducts containing an air-filled, spongy substance leading to a thin layer of the same airfilled material lining the shell. Insecticides with suitable wetting properties will readily fill layers of this type, which are of common occurrence in insect eggs, and they are then separated from the contents of the egg only by the thin wax layer. Some eggs deposit a further layer of impermeable material inside the wax. The formation of this layer may be correlated with a great increase in the resistance of the egg to insecticides when it reaches a certain age. It may become susceptible again in the late stages of development when this inner membrane is dissolved; or the embryo may be poisoned by the quantities of insecticide that have been held in this protective membrane and liberated during its solution. Clearly the age of eggs must be most carefully controlled in making ovicidal tests.

Dr. C. Potter described a number of researches by himself and his colleagues, Dr. K. A. Lord and Dr. A. H. McIntosh, which served to illustrate some of the physical and biochemical factors concerned in insecticidal action. The size of particles of an insecticide applied externally may greatly influence the toxic action. Small particles of rotenone are several hundred times more toxic than layer particles. With DDT the difference is less evident-perhaps because it is so much more soluble in the lipoid layer of the cuticle that its rate of entry is not greatly influenced by being in finely particulate form. The same correlation between the effect of particle size on toxicity, on one hand, and lipoid solubility, on the other, is seen when the poisons are injected into the blood stream. Temperature may influence the toxic action of insecticides in several quite different ways. Pyrethrins, DDT and some other poisons are much more toxic if the insects are kept at a low temperature after spraying. This is mainly an effect on motabolism. But at high temperatures insects move more actively; they may therefore pick up more of the insecticide from the environment and thus show an increased mortality at higher tem. peratures. Moreover, at low temperatures the more rapid solubility of small particles is accentuated so that their relative toxicity is even greater. The action of insecticides in metabolism was illustrated with reference to the organo-phosphorus compounds. These are powerful inhibitors of choline-esterase, and when an analogous series of organo-phosphorus insecticides is examined there is a partial correlation between choline-esterase inhibition and toxicity. But there are other esterases present in insects which do not hydrolyse acetylcholine, and it has been found that these also are inhibited by the organophosphorus insecticides; and it may well be that this effect is involved in their insecticidal actionfor example, when they kill insect eggs at an early stage of development. A knowledge of the differences between the esterase systems of insects and mammals might serve as a basis for selecting chemicals toxic to insects but relatively non-toxic to man.

The interrelations between physiology, ecology and cultural control were illustrated and discussed with reference to the sheep tick Ixodes ricinus, an important 
carrier of a number of serious diseases in sheep on hill farms. Dr. A. Milne described the general features in the ecology of this tick. It is widely spread throughout the hill sheep-farming areas of Great Britain, but occurs only in those localities where the pastures are rough, with a thick layer or 'mat' of dead and dying vegetation at the base of the herbage. The humidity in this mat is always about 100 per cent, and it appears to be this high humidity which is the limiting factor in the distribution of the tick. This is not surprising when it is realized that the sheep tick is not resistant to desiccation, and yet during its life-cycle of two to three years it spends only about six weeks in feeding on its host. For the rest of its life it is lying inactive in the moist mat or is at the tips of the grass stems waiting for a passing host. In most of the country there is only one period, in the late spring and early summer, during which the ticks are active in this way. But there are some localities, notably in the west of England, where there is a second peak of activity in the autumn. (An apparent peak in the summer which has been described in Wales is spurious and has been wrongly inferred from the gradual rise in the numbers of ticks upon stock introduced to infested pastures.) Pasture improvement, with the elimination of the humid 'mat', will effectively eradicate the sheep tick-though this is seldom economically practicable on the hill farms.

Dr. J. Allan Campbell described his detailed studies of the developmental cycle of the sheep tick in Nature. The temperature in the natural environment ranges between $-2^{\circ} \mathrm{C}$. and $+15^{\circ} \mathrm{C}$. At these temperatures development and egg-laying proceed at much slower rates than has been inferred from studies in the laboratory. In the normal cycle the tick at each stage of its development feeds in the spring or early summer, moults or oviposits during the summer, and overwinters in the unfed state. But there is a second cycle in which the ticks feed in the autumn, pass the winter in the egg or in the engorged state, and hatch or moult in the spring. It is these two populations, between which there seems to be little interchange, which are responsible for the two peaks of activity in the spring and in the autumn. The threshold temperature for development of the egg is $7^{\circ} \mathrm{C}$.; but the eggs laid by the ticks of the autumn feeding cycle will not develop, even at $10-20^{\circ} \mathrm{C}$., until they have been exposed to severe cold for a good many weeks.

The physiology of the sheep tick, as described by Dr. A. D. Lees, goes far towards explaining the observations made on its ecology. When compared with a series of other ticks, 1xodes ricinus has a cuticular wax of very poor waterproofing powers, and it is this which limits its distribution. The closely related dog tick Ixodes canisuga, which has a cuticular wax of higher melting point, is alone able to survive in the kennels of the sheep dogs, although both species are picked up by them. So long as Ixodes remains in a nearly saturated atmosphere, it can absorb water vapour actively through its cuticle and maintain its water content. When it becomes active in the spring, the unfed tick shows a negative response to gravity and an avoidance of high humidity which lead it to the tips of the grasses, where its sensitive responses to vibration, to passing shadows and to eddies of warm air and smell enable it to cling to a passing host. The unfed tick at each stage of its life-cycle can remain latent in the humid mat for many months. The length of time it can resist starvation is determined by its reserves of fat carried over from the previous stage. After becoming active and resting for some time at the tips of the grasses, it loses moisture and it then returns to the mat to restore its water content by the active uptake of water vapour. 'This form of activity is necessary if the tick is to secure a meal to enable it to grow or reproduce. But it soon exhausts the limited reserves of fat, and the active tick dies of starvation far sooner than the more sluggish individual which remains dormant at the base of the vegetation.

In closing the discussion, Dr. Wigglesworth said that the sheep tick problem was chosen because it illustrates particularly well the way in which a knowledge of the detailed physiology of a pest enables the applied biologist to think clearly and rationally about it and to see his problems in a new light. That is part of the debt of applied entomology to insect physiology. But there is a debt of perhaps even greater magnitude in the other direction. Many of the most important discoveries in insect physiology, and indeed in biology in general, have resulted from the intellectual stimulus of contact with some practical problem.

\section{BUILDING RESEARCH CONGRESS, 1951}

7 HE Building Research Congress held in London during September 11-20 was the outcome of co-operation between some two-dozen professional institutions and trade federations interested in build. ing and civil engineering construction, the Depart. ment of Scientific and Industrial Research and the Ministry of Works. As the first of its kind ever to be held, it aroused much interest both in Great Britain and overseas, and among its 1,400 members were representatives of more than fifty countries; of the eighty-eight papers presented forty-five were by authors from outside Great Britain. The enthusiasm with which the Congress was greeted was a clear indication of the need for such a conference, and the large attendance from abroad was a tribute to the regard in which the pioneer work of Great Britain in this field is held. The Congress, the organization of which was largely undertaken by the Building Research Station of the Department of Scientific and Industrial Research, met under the presidency of Lord Samuel.

The opening session, held at the Institution of Civil Engineers on the morning of September 11, was the occasion of the first of Lord Samuel's thoughtprovoking contributions. He directed attention to the effect environment - man-made as well as naturalhas had on individuals and pointed out the effect that building research could therefore have on individual and national life. Dr. F. M. Lea, director of building research in the Department of Scientific and Industrial Research, traced the growth of organized building research and made a plea for still closer co-operation of industry in the application of its results. In the afternoon members were the guests of the Government at a reception at Lancaster House, and later, under the auspices of the Parliamentary and Scientific Committee, visited the new House of Commons Chamber and other parts of the Palace of Westminster.

For the technical sessions, the Congress was organized in three divisions, dealing with the engin- 